\title{
Parenteral iron prophylaxis: a convenient alternative for antenatal women who do not consume oral iron
}

\author{
Suvarna Rai* \\ Department of Obstetrics and Gynecology, Malla Reddy Institute of Medical Sciences, Hyderabad, Telangana, India
}

Received: 24 July 2017

Accepted: 27 July 2017

\section{*Correspondence:}

Dr. Suvarna Rai,

E-mail: drsuvarnarai@gmail.com

Copyright: $\odot$ the author(s), publisher and licensee Medip Academy. This is an open-access article distributed under the terms of the Creative Commons Attribution Non-Commercial License, which permits unrestricted non-commercial use, distribution, and reproduction in any medium, provided the original work is properly cited.

\begin{abstract}
Background: A large number of antenatal women have difficulty consuming oral iron due to its well-known side effects. A simple alternative for it needs to be found. Aim and objective was to study the efficacy of parenteral iron prophylaxis as an alternative for antenatal women who are not able to consume oral iron.

Methods: A prospective case control study was conducted at a tertiary care centre in Hyderabad city, India from March 2016- March 2017. 73 non-anemic antenatal women between 14-24 weeks who were not taking oral iron supplementation were identified. 39 of them were willing for parenteral iron supplementation were included in Cases group and 34 who were not taking iron supplementation in any form were controls. Cases were administered three doses of IV Iron sucrose $200 \mathrm{mg}$ in $100 \mathrm{ml}$ normal saline between 24-28 weeks, 28 - 32 weeks and 35-37 weeks Hemoglobin was checked again at 32 weeks, 36 weeks, just prior to and on $3^{\text {rd }}$ day post-delivery. Data obtained was analyzed using SPSS software.

Results: $67 \%$ of antenatal women discontinued oral iron due to its gastric side effects. No bias took place during selection of cases and controls. 7.69\% of the 'cases group' developed anemia despite parenteral prophylaxis. All of them were diagnosed as mild anemia. 70.59\% of the 'controls group' developed anemia eventually of which 8 were mild, 13 were moderate, 3 were severe and none were very severe. Mostly women became anemic after delivery. About 59\% of antenatal women in cases group had no adverse effects with Iron Sucrose Injections, 8 of them had itching or rash and 9 of them complained of brownish discoloration of urine.11 of them had pain at the infusion site and only 1 of them had fever on administering parenteral therapy. None of these were severe enough to cause discontinuation of parenteral iron administration. No statistically significant difference could be found in maternal and perinatal morbidity and mortality between the two groups. The mean cost of parenteral iron prophylaxis was Rs. 1650.

Conclusions: Women who do not take oral Iron supplementation in pregnancy are more prone to develop anemia subsequently. The commonest cause of non-compliance to oral iron is gastric intolerance. 3 doses of Intravenous Iron Sucrose $200 \mathrm{mg}$ prevents anemia in antenatal women who do not take oral iron supplementation. Hence, it can now be considered a convenient option for them.
\end{abstract}

Keywords: Antenatal anemia, Non-compliance to oral iron, Oral iron intolerance, Prophylactic parenteral iron therapy

\section{INTRODUCTION}

Pregnancy is a delicate stage in a woman's life where her nutritional demands completely change. She has to keep up to the increased requirement of several nutrients. Of a special mention is iron which plays a pivotal role in maintaining the health of both mother and the fetus. The daily iron requirement for an antenatal woman is 4$6 \mathrm{mg} /$ day in second trimester and that in third trimester is $10-12 \mathrm{mg} /$ day. ${ }^{1}$ This high requirement is difficult to meet 
by just dietary modifications. ${ }^{2}$ Hence, prophylactic oral iron is prescribed to all antenatal women to prevent maternal anemia. It is usually administered as oral tablets or oral syrups. WHO recommends daily supplementation of $60 \mathrm{mg}$ oral iron for all pregnant women to prevent maternal iron deficiency anemia. ${ }^{2}$ Ministry of Health and family welfare recommends a minimum of $100 \mathrm{mg}$ of elemental iron be supplemented for atleast 100 days during antenatal period to prevent maternal anemia. ${ }^{3}$

Recent Cochrane review suggests there is an increased risk of maternal anemia in those antenatal women who do not consume oral iron supplementation. ${ }^{4} 2015$ Cochrane database suggests even intermittent oral iron prophylaxis can prevent anemia in pregnancy. 5,6

But many antenatal women are not able to consume iron by oral route even intermittently due to its well-known and common side effects. Many of them tend to discontinue the prescribed oral tablets due to adverse effects like nausea, vomiting, severe gastritis, gastro esophageal reflux, constipation and blackish discolouration of stools. In addition to these many women complain that oral iron syrups have an unpalatable metallic taste that is difficult to consume and induce aesthetic problems like gradual blackish discolouration of teeth. ${ }^{7}$ Despite repeated counseling a significant number of antenatal women either consume these oral medications bizarrely and many even ultimately discontinue them leading to depleted iron stores and mostly maternal anemia. Once anemia develops therapeutic parenteral iron therapy and blood transfusions as required are administered to the mother. Blood transfusions are well known for their adverse reactions and complications which further worsen the morbidity and mortality associated with anemia. ${ }^{8}$

Parenteral Iron can be an effective alternative to those who don't consume oral iron to prevent maternal anemia. The present study was planned to test the same.

\section{METHODS}

The present study was a prospective study conducted from March 2016 March 2017 at Malla Reddy Institute of medical Sciences, a tertiary care centre at the city of Hyderabad, India. All women who attended the antenatal clinic between 14- 24 weeks were identified. Of these women who were non-anemic and were not taking oral iron for any reason were included in the study as study population. Anemia was defined in the present study as Hemoglobin $<11 \mathrm{~g} / \mathrm{dl}$ as per WHO definition. ${ }^{9}$ Mild anemia was $\mathrm{Hb}$ between $9-11 \mathrm{~g} / \mathrm{dl}$, moderate anemia was between $7-9 \mathrm{~g} / \mathrm{dl}$, severe anemia was $\mathrm{Hb} 4-7 \mathrm{~g} / \mathrm{dl}$ and very severe anemia was $\mathrm{Hb}<4 \mathrm{~g} / \mathrm{dl}$. Those women who had multiple pregnancy, pre-eclampsia, asthma, COPD, liver and renal disorders and those who did not want to be a part of this study were excluded.
A written informed consent was taken from them in their own language. Those who were willing to take parenteral iron supplementation were included in cases group and those who were not taking iron supplementation in any form were controls. Cases were administered three doses of Injection Iron Sucrose $200 \mathrm{mg}$ diluted in $200 \mathrm{ml}$ normal saline was administered intravenously over 1 hour at intervals between 24-28 weeks, 28-32-week sand 35-37 weeks. Repeat hemoglobin was checked and recorded at 32 weeks, 36 weeks, and prior to delivery and on $3^{\text {rd }}$ day after delivery and were labeled as $\mathrm{Hb} 1,2,3$ and 4 respectively. As soon as anemia was detected in any of these Hemoglobin estimations, the participant was omitted from the study and followed standard guidelines for anemia management according to its severity. All women were followed up till 6 weeks postpartum.

\section{Statistical analysis}

The data obtained was processed using Microsoft Excel software for data entry and statistical analysis was done using Statistical Package for Social Software (SPSS). Chi square test was applied to know the association between variable. $\mathrm{P}$ value less than or equal to 0.05 was considered statistically significant.

\section{RESULTS}

We enrolled 117 patients in our study of whom we lost follow up with 44 patients. The remaining 73 were the final study population that was analyzed. Of these 39 were "cases" who were administered parenteral Iron prophylaxis and 34 were "Controls" who were not consuming Iron supplementation in any form.

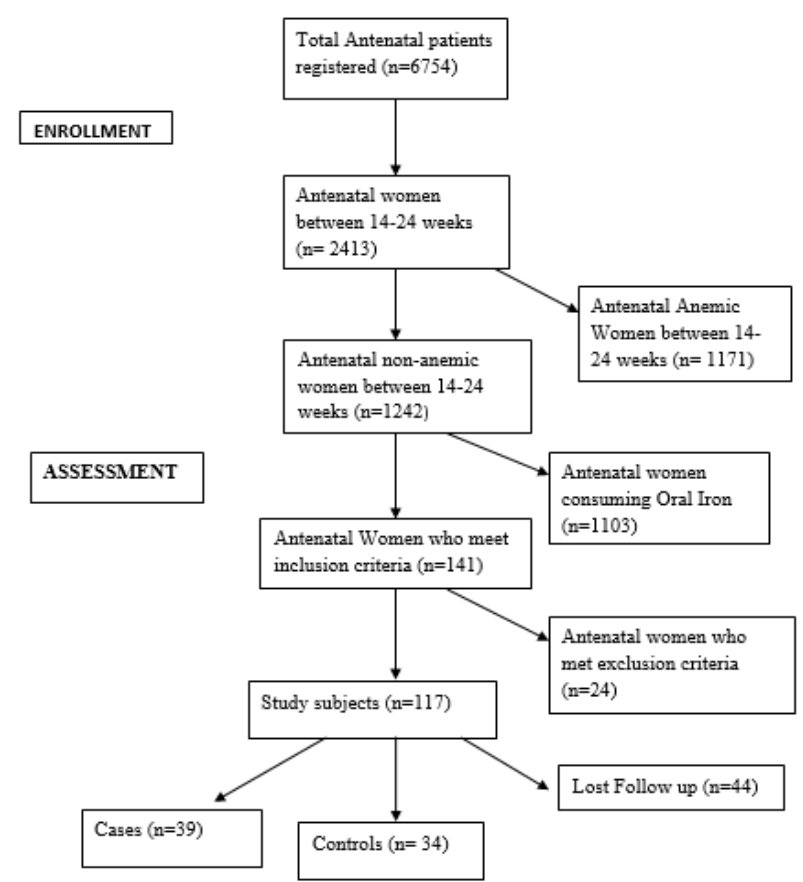

Figure 1: Flow of participants during the study. 


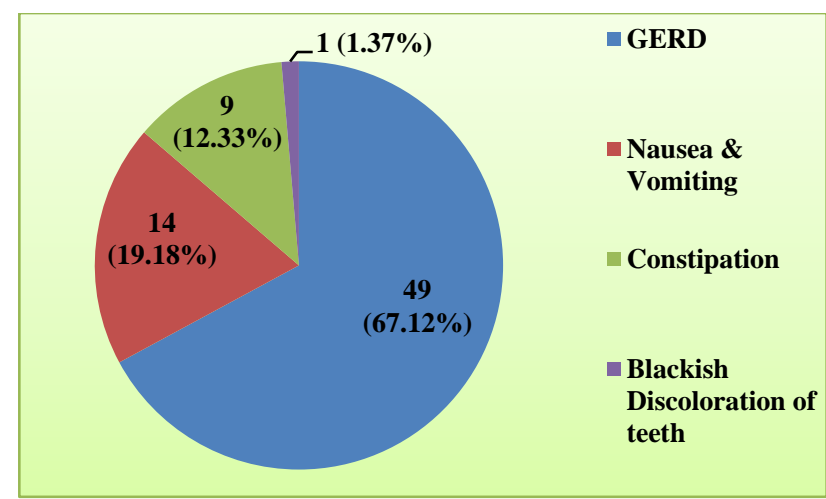

Figure 2: Reasons for non-compliance with oral iron.

All 73 subjects were interviewed for the reason for not consuming oral iron. The commonest reason was the severe gastric side effects like gastritis, Gastro esophageal reflux and Gastric ulcers. Figure 2 depicts the same.

Table 1: Participant characteristics.

\begin{tabular}{|c|c|c|c|}
\hline Characteristics & $\begin{array}{l}\text { Cases } \\
(n=39)\end{array}$ & $\begin{array}{l}\text { Controls } \\
(\mathrm{n}=34)\end{array}$ & $\begin{array}{l}p \\
\text { value }\end{array}$ \\
\hline Mean age (years) & $25.55 \pm 4.12$ & $25.34 \pm 4.15$ & 0.762 \\
\hline Mean weight (kg) & $56.89 \pm 9.04$ & $54.23 \pm 9.08$ & 0.831 \\
\hline Mean BMI & $23.31 \pm 3.54$ & $22.76 \pm 4.52$ & 0.195 \\
\hline \multicolumn{4}{|l|}{ Parity } \\
\hline Primigravida & 19 & 16 & \multirow{2}{*}{0.586} \\
\hline Multigravida & 20 & 18 & \\
\hline $\begin{array}{l}\text { Gestational age at } \\
\text { recruitment (weeks) }\end{array}$ & $21 \pm 6$ & $22 \pm 2$ & 0.878 \\
\hline $\begin{array}{l}\text { Hb at recruitment } \\
(\mathrm{g} / \mathrm{dl})\end{array}$ & $11.5 \pm 0.15$ & $11.9 \pm 0.11$ & 0.434 \\
\hline
\end{tabular}

No bias took place during selection of cases and controls because the mean age, weight, BMI, parity, gestational age and Hemoglobin level during recruitment were comparable with no significant $\mathrm{p}$ value as shown in Table 1 .

Table 2: Hemoglobin estimation outcomes.

\begin{tabular}{|lll|} 
& Cases $(\mathrm{n}=39)$ & Controls $(\mathrm{n}=34)$ \\
\hline $\mathrm{Hb} 1<11 \mathrm{~g} / \mathrm{dl}$ & 0 & $4(11.76 \%)$ \\
\hline $\mathrm{Hb} 2<11 \mathrm{~g} / \mathrm{dl}$ & 0 & $7(20.58 \%)$ \\
\hline $\mathrm{Hb} 3<11 \mathrm{~g} / \mathrm{dl}$ & $1(2.56 \%)$ & $5(14.71 \%)$ \\
\hline $\mathrm{Hb} 4<11 \mathrm{~g} / \mathrm{dl}$ & $2(5.13 \%)$ & $8(25.53 \%)$ \\
\hline
\end{tabular}

3 patients $(7.69 \%)$ of the cases group developed anemia despite parenteral iron prophylaxis. All of them were diagnosed as mild anemia which was further treated with parenteral iron therapy but in a dosage, that was calculated according to Ganzoni formula. ${ }^{4}$

Iron Requirement $=$ Body weight $\times \mathrm{Hb}$ deficit $\times 2.4+500 \mathrm{mg}$ for Iron stores

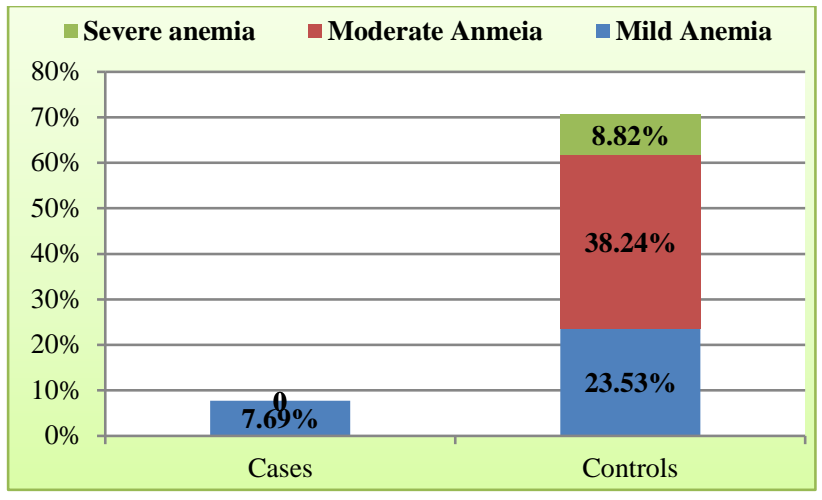

Figure 3: Occurrence of anemia in study population.

$24(70.59 \%)$ of the control group developed anemia eventually of which $8(23.53 \%)$ were mild and 13 $(38.24 \%)$ were moderate. All subjects with mild anemia at any gestational age and moderate anemia <36 weeks were treated with parenteral iron therapy in dose calculated from the above-mentioned formula. $3(8.82 \%)$ of the cases developed severe anemia when checked on $3^{\text {rd }}$ day after delivery and were treated with blood transfusion. None of them developed very severe anemia. All of these findings were statistically significant. Figure 3 illustrates same for clearer understanding.

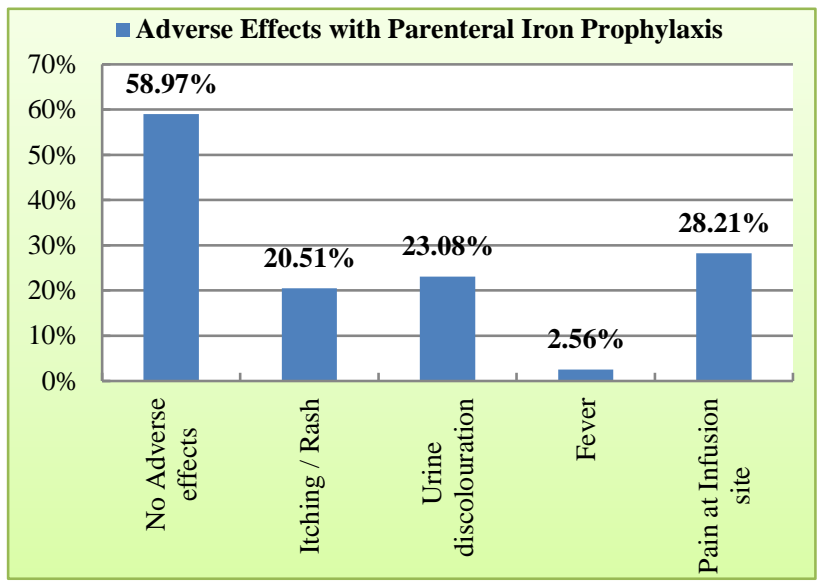

Figure 4: Adverse effects of parenteral iron among cases group.

$23(58.97 \%)$ women of the cases group faced no adverse effects with parental iron. $8(20.51 \%)$ of them had itching or rash and $9(23.08 \%)$ of them complained of brownish discoloration of urine. $11(28.21 \%)$ of them had pain at the infusion site and only $1(2.56 \%)$ of them had fever on administering parenteral therapy. None of these were severe enough to cause discontinuation of parenteral iron administration.

According to present study, there was no statistically significant difference between period of delivery, occurrence of PPH, mean birth weight of baby, APGAR Score, post-delivery/post-operative wound healing and parenteral iron prophylaxis and those who took no iron 
supplementation at all. The mean cost of parenteral iron prophylaxis was Rs. 1650.

Table 3: Therapy related outcomes.

\begin{tabular}{|c|c|c|c|}
\hline & $\begin{array}{l}\text { Cases } \\
(n=39)\end{array}$ & $\begin{array}{l}\text { Controls } \\
(n=34)\end{array}$ & $\begin{array}{l}\mathrm{p} \\
\text { value }\end{array}$ \\
\hline Maternal anemia & $03(7.69 \%)$ & $24(70.59 \%)$ & 0.019 \\
\hline PPH & $01(2.56 \%)$ & $02(5.88 \%)$ & 0.281 \\
\hline $\begin{array}{l}\text { Postdelivery/ } \\
\text { Postoperative } \\
\text { Wound infection } \\
\text { and gaping }\end{array}$ & $02(5.13 \%)$ & $01(2.94 \%)$ & 0.372 \\
\hline \multicolumn{4}{|c|}{ Timing of delivery } \\
\hline Preterm & $04(10.26 \%)$ & $05(14.71 \%)$ & \multirow{3}{*}{0.315} \\
\hline Term & $35(89.74 \%)$ & $29(85.29 \%)$ & \\
\hline Post term & 00 & 00 & \\
\hline \multicolumn{4}{|c|}{ Mean APGAR Score } \\
\hline $1 \mathrm{~min}$ & 8.72 & 8.08 & \multirow{2}{*}{0.419} \\
\hline $5 \mathrm{~min}$ & 9.04 & 9.02 & \\
\hline $\begin{array}{l}\text { Mean birth } \\
\text { weight }\end{array}$ & $3.26 \pm 0.43$ & $2.62 \pm 0.64$ & 0.042 \\
\hline LBW & $06(15.38 \%)$ & $05(14.71 \%)$ & 0.812 \\
\hline
\end{tabular}

\section{DISCUSSION}

2012 Cochrane review concluded that women who do not take any iron supplementation had significantly lower hemoglobin in pregnancy and post-partum period. ${ }^{4}$ The present study found similar results.

The same Cochrane review also concluded that those women who took oral iron supplementation also had higher baby birth weight, lower incidence of preterm births and low birth weight babies which did not concur with the present study. ${ }^{4}$

There are very few studies that suggest an alternative to those who are non-compliant with oral iron supplementation. One such study was conducted by Gogineni et al in 2015 which compared oral iron prophylaxis to parenteral iron prophylaxis in 100 patients. For parenteral prophylaxis Injection Iron sucrose 200mg was administered in three doses. ${ }^{10}$ They concluded that there was no difference in the mean Hemoglobin rise attained by both oral and parenteral iron prophylaxis in pregnancy which was similar to the present study's conclusion.

A larger trial conducted in Switzerland on 260 antenatal women who were selected between 21-24 weeks and were administered oral and parenteral iron prophylaxis. ${ }^{11}$ They further studied parenteral iron prophylaxis by administering two and three doses of 200mg Iron sucrose. They observed no significant difference in occurrence of anemia between oral and both dosages of parenteral iron prophylaxis. There was no difference in maternal and perinatal outcome between both groups as was found in the present study.
Also, of a special mention is the fact that there is limited data on whether Iron Sucrose is safe in first trimester; hence the drug was only administered after complete organogenesis took place in the present study. ${ }^{12}$

\section{CONCLUSION}

Women who do not take oral Iron supplementation in pregnancy are more prone to develop anemia subsequently. The commonest cause of non-compliance to oral iron is gastric intolerence. 3 doses of Intravenous Iron Sucrose $200 \mathrm{mg}$ prevents anemia in antenatal women who do not take oral iron supplementation. Hence, it can now be considered a convenient option for them.

\section{Funding: No funding sources}

Conflict of interest: None declared

Ethical approval: The study was approved by the Institutional Ethics Committee

\section{REFERENCES}

1. Bothwell TH. Iron requirements in pregnancy and strategies to meet them. Am J Clin Nutr. 2000;72(1):257s-64s.

2. Daily iron and folic acid supplementation in pregnant women. Geneva: World Health Organization; 2012 [archived](http://www.who.int/nutrition/publications /micronutrients/guidelines/daily_ifa_supp_pregnant_ women/en/).

3. Ministry of Health and Family Welfare GoI, Office memorandum. Revised Operational strategy for oral Iron for pregnant women. November 2014. Available at https://wbxpress.com/wpcontent/uploads/2014/12/H-3701.pdf

4. Peña- Rosas JP, De- Regil LM, Dowswell T, Viteri FE. Daily oral iron supplementation during pregnancy. Cochrane Database Syst Rev. 2012;12:CD004736.

5. Peña- Rosas JP, De- Regil LM, Gomez Malave H, Flores- Urrutia MC, Dowswell T. Intermittent oral iron supplementation during pregnancy. Cochrane Database Syst Rev. 2015 Oct 19;(10):CD009997.

6. Casanueva E, Viteri FE, Mares-Galindo M, MezaCamacho C, Loría A, Schnaas L, Valdés-Ramos R. Weekly iron as a safe alternative to daily supplementation for nonanemic pregnant women. Arch Med Res. 2006;37(5):674-82.

7. Lindgren S, Wikman O, Befrits R, Blom H, Eriksson A, Grännö C, Ung KA et al. Intravenous iron sucrose is superior to oral iron sulphate for correcting anaemia and restoring iron stores in IBD patients: a randomized, controlled, evaluator-blind, multicentre study. Scand J Gastroenterol. 2009;44(7):838-45.

8. Maxwell MJ, Wilson MJ. Complications of blood transfusion. Continuing Edu Anaesthesia, Crit Care Pain. 2006;6(6):225-9.

9. Dutta DC. Text book of obstetrics including perinatology and contraception. Anaemia in 
pregnancy. 6th ed. Calcutta: New Central Book Agency (P) Ltd;2004:262-7.

10. Gogineni S, Vemulapalli P. Comparative Study of Parenteral Iron Sucrose Vs Oral Ferrous Ascorbate for Prophylactic Iron Therapy in Pregnancy. IOSRJDMS. 2015;14(12):95-97.

11. Bencaiova G, von Mandach U, Zimmermann R. Iron prophylaxis in pregnancy: intravenous route versus oral route. Eur J Obstet Gynecol Reprod Biol. 2009;144(2):135-9.
12. Pavord S, Myers B, Robinson S et al. UK guidelines on the management of iron deficiency in pregnancy. Br J Haemtol. 2012;156:588-600.

Cite this article as: Rai S. Parenteral iron prophylaxis: a convenient alternative for antenatal women who do not consume oral iron. Int J Reprod Contracept Obstet Gynecol 2017;6:3832-6. 